\section{RMD Open}

Rheumatic \& Musculoskeletal Diseases

\title{
Comparison of carotid artery ultrasound and Framingham risk score for discriminating coronary artery disease in patients with psoriatic arthritis
}

\author{
Isaac T Cheng, ${ }^{1}$ Ka Tak Wong, ${ }^{2}$ Edmund K Li, ${ }^{1}$ Priscilla C H Wong, ${ }^{3}$ Billy T Lai, ${ }^{4}$ \\ Isaac C Yim, ${ }^{4}$ Shirley K Ying, ${ }^{5}$ Kitty Y Kwok, ${ }^{6}$ Martin Li, ${ }^{1}$ Tena K Li, ${ }^{1}$ Jack J Lee, ${ }^{7}$ \\ Alex P Lee, ${ }^{1}$ Lai-Shan Tam (1) 1
}

To cite: Cheng IT, Wong KT, Li EK, et al. Comparison of carotid artery ultrasound and Framingham risk score for discriminating coronary artery disease in patients with psoriatic arthritis. RMD Open 2020;6: e001364. doi:10.1136/ rmdopen-2020-001364

- Supplemental material is published online only. To view please visit the journal online (http://dx.doi.org/10.1136/rmdo pen-2020-001364).

Received 17 June 2020 Revised 13 August 2020 Accepted 5 September 2020

Check for updates

(C) Author(s) (or their employer(s)) 2020. Re-use permitted under CC BY-NC. No commercial re-use. See rights and permissions. Published by BMJ.

For numbered affiliations see end of article.

Correspondence to Lai-Shan Tam; Istam@cuhk. edu.hk

\section{ABSTRACT}

Objectives This study aimed to assess the performance of carotid ultrasound (US) parameters alone or in combination with Framingham Risk Score (FRS) in discriminating patients with psoriatic arthritis (PsA) with and without coronary artery disease (CAD).

Methods Ninety-one patients with PsA (56 males; age: 50 \pm 11 years, disease duration: $9.4 \pm 9.2$ years) without overt cardiovascular (CV) diseases were recruited. Carotid intimamedia thickness (cIMT), the presence of plaque and total plaque area (TPA) was determined by high-resolution US CAD was defined as the presence of any coronary plaque on coronary CT angiography (CCTA). Obstructive-CAD (0-CAD) was defined as $>50 \%$ stenosis of the lumen.

Results Thirty-five (38\%) patients had carotid plaque. Fifty-four (59\%) patients had CAD (CAD+) and 9 (10\%) patients had $0-C A D(0-C A D+)$. No significant associations between the presence of carotid plaque and $C A D$ were found. However, CIMT and TPA were higher in both the CAD + and 0-CAD+ group compared with the CAD- or 0-CADgroups, respectively. Multivariate logistic regression analysis revealed that mean cIMT was an independent explanatory variable associated with CAD and $0-C A D$, while maximum cIMT and TPA were independent explanatory variables associated with 0-CAD after adjusting for covariates. The optimal cut-offs for detecting the presence of CAD were FRS $>5 \%$ and mean CIMT at $0.62 \mathrm{~mm}$ (AUC: 0.71 ; sensitivity: $67 \%$; specificity: $76 \%$ ), while the optimal cut-offs for detecting the presence of 0-CAD were FRS $>10 \%$ in combination with mean cIMT at $0.73 \mathrm{~mm}$ (AUC: 0.71 ; sensitivity: $56 \%$; specificity: $85 \%$ ).

Conclusion US parameters including CIMT and TPA may be considered in addition to FRS for CV risk stratification in patients with PsA.

Cardiovascular (CV) and cerebrovascular morbidity is increased by $43 \%$ and $22 \%$. respectively, in patients with psoriatic arthritis (PsA) compared with the general population. ${ }^{1} \mathrm{CV}$ disease (CVD) risk assessment is recommended for all patients with rheumatoid arthritis (RA), ankylosing

\section{Key messages}

What is already known about this subject?

- Patients with psoriatic arthritis (PSA) are of increased risk of cardiovascular disease.

What does this study add?

- Performance of Framingham risk score (FRS) in discriminating patients with and without coronary artery disease (CAD) is suboptimal.

- This study is the first to report the association between carotid and coronary artery disease in patients with PSA using carotid ultrasound and coronary CT angiography (CCTA).

How might this impact on clinical practice?

- Data from this study suggest that a combination of Framingham risk score and carotid intima-media thickness may be considered for cardiovascular risk stratification in these patients.

spondylitis or PsA at least once every 5 years, so that lifestyle advice and CVD preventive treatment can be initiated when indicated. ${ }^{2}$ Unfortunately, traditional CV risk scores including the Framingham risk score (FRS), ${ }^{3}$ QRISK2, ${ }^{4}$ Systematic COronary Risk Evaluation (SCORE) ${ }^{5}$ and American College of Cardiology and the American Heart Association (ACC/AHA) 10-year atherosclerotic CV disease risk (ASCVD) ${ }^{6}$ underestimated CV risks $^{7-10}$ in patients with PsA.

Coronary CT angiography (CCTA) is a noninvasive and accurate method to assess coronary atherosclerosis, which is closely associated with cardiac events in the general population. ${ }^{11-13}$ Further CV risk stratification is possible by detecting the presence of highrisk plaques (non-calcified plaque (NCP) and mixed plaque (MP)). ${ }^{14}{ }^{15}$ We and others have demonstrated that patients with PsA had 
increased prevalence, burden and severity of coronary atherosclerosis assessed using CCTA, ${ }^{10}{ }^{16}$ supporting the notion that a more aggressive $\mathrm{CV}$ evaluation strategy should be considered in these patients. ${ }^{10}$ However, there are concerns regarding costs and radiation exposure using CCTA or even coronary artery calcium as a screening tool.

Carotid ultrasound (US) is a non-invasive imaging technique which can identify the presence of carotid plaque and increased carotid intima-media thickness (cIMT). The burden of carotid atherosclerosis is associated with an increased risk of developing future $\mathrm{CV}$ events in patients with psoriatic disease. ${ }^{17}$ Because CCTA has been shown to have accuracy comparable with invasive angiography, ${ }^{18}$ it is perhaps a superior method of assessing coronary artery disease (CAD) rather than using carotid artery US as a surrogate marker of subclinical atherosclerosis. European League Against Rheumatism (EULAR) suggested a multiplication factor of 1.5 should be added to the FRS to address the augmented CV risk in RA (modified FRS). ${ }^{2}$ Nevertheless, modified FRS (mFRS) only yield moderate improvement in identification of CAD on CCTA. ${ }^{19}{ }^{20}$ A previous study including mainly patients with RA with carotid plaques showed that a combination of ultrasonographic measurements rather than the presence of carotid plaque alone may be useful in risk stratification for $\mathrm{CAD} .{ }^{21}$ Whether this is also true in patients with PsA would need to be confirmed. Moreover, the prevalence of CAD in patients with PsA without carotid plaques remained uncertain.

The aims of this study were (1) to ascertain the correlation between carotid artery atherosclerosis by carotid US with $\mathrm{CAD}$, obstructive $\mathrm{CAD}(\mathrm{O}-\mathrm{CAD})$ and three-vessel disease (TVD) assessed using CCTA; and (2) the utility of carotid US parameters in combination with traditional CV risk score in discriminating patients with $\mathrm{CAD}$ and $\mathrm{O}-\mathrm{CAD}$.

\section{PATIENTS AND METHODS}

\section{Patients}

This is a post-hoc analysis of the PsA CCTA study and the effect of achieving minimal disease activity (MDA) on the progression of subclinical atherosclerosis and arterial stiffness study (MDA vascular study). ${ }^{1022}$ Ninety-one consecutive patients with PsA without overt CVD attending the outpatient clinic of the Prince of Wales Hospital (PWH) who were recruited for the MDA vascular study and had carotid US performed at baseline were referred for CCTA. Patients who had successfully performed CCTA and carotid US assessment were included in this analysis. The study was approved by the Ethics Committee of the Chinese University of Hong Kong with written informed consent obtained from all participants. The study was conducted in compliance with the declaration of Helsinki.

\section{Clinical assessment}

Clinical assessments in all subject were described before. ${ }^{22}$ Briefly, anthropomorphic measurements, disease features including pain, physicians' and patients' global assessments, number of tender and swollen joints (using the 68 tender/ 66 swollen joint count), number of joints irreversibly damaged, enthesitis, number of digits with dactylitis, levels of acute-phase reactant including erythrocyte sedimentation rate (ESR) and (CRP) and functional disability as indicated by the health assessment questionnaire-disability index (HAQ-DI) were included. Drug history was retrieved from case notes or elicited during the clinical assessment. Achievement of treatment target was assessed using $\mathrm{MDA}^{23}$ and disease activity was assessed using Disease Activity in Psoriatic Arthritis (DAPSA) ${ }^{24}$ Fasting blood glucose and lipid profile (total cholesterol (TC), high-density lipoproteincholesterol (HDL), low-density lipoprotein-cholesterol (LDL) and triglycerides) were checked before CCTA and carotid US exam. FRS was used for assessing CV risk (FRS $<10 \%$ indicates low CV risk, 10-19\% indicates intermediate risk while $\geq 20 \%$ indicates high risk). ${ }^{25}$

\section{Coronary atherosclerosis assessment}

CCTA scans were performed as described before ${ }^{10}$ by a 64-multidetector row Lightspeed VCT scanner (GE Healthcare), in accordance with the protocol employed in the ACCURACY triall ${ }^{26}$ and were analysed by an experienced radiologist (KTW). Briefly, the presence, site and type of coronary plaque (including NCP, CP and MP) were reported. CAD was defined as the presence of any coronary plaque. Coronary arteries were standardised to American Heart Association 15-segment model. ${ }^{27} \mathrm{Seg}$ ment involvement score (SIS) represented the total number of segments harbouring plaque. Lesions rendering over $50 \%$ stenosis of the lumen were considered as O-CAD. TVD was defined as the presence of coronary plaque in left anterior descendent branch, left circumflex branch and right coronary artery. For patients having multiple plaques, the most stenotic one was recorded.

\section{Carotid intima-media thickness (cIMT) and plaque}

Measurement of cIMT, plaque and total plaque area (TPA) was performed by high-resolution B-mode US machine (Philips EPIQ7) as described before. ${ }^{22}$ A single operator who were blinded to the CCTA results performed the US scan and corresponding offline measurement of US parameters. The mean and maximum cIMT in bilateral distal common carotid artery, bulb and proximal internal carotid artery were reported. Plaque was defined as a localised thickening $>1.2 \mathrm{~mm}$ that do not uniformly involve the whole artery. TPA was the sum of size of all plaques in six segments. Reproducibility of cIMT was 0.97 .28

\section{Statistical analysis}

Statistical analyses were performed using the Statistics Package for Social Sciences (SPSS version 24.0) and the MATLAB (R2019b, The MathWorks Inc, Natick, Massachusetts). Descriptive statistics were used for demographic and clinical variables included frequencies, percentage, means and $\mathrm{SD}$, median and IQR. 
Comparisons in demographic and clinical characteristics between subject with or without CAD, O-CAD and TVD were performed using $\chi^{2}$ test, independent samples t-test and Mann-Whitney U-test, depending on distribution of data. Univariate analyses were performed to look for covariates that were associated with CAD, O-CAD and TVD. The analyses on the association of carotid atherosclerosis and CAD, O-CAD and TVD were performed by the multivariate logistic regression models with adjustment for covariates that were associated with $\mathrm{CAD}, \mathrm{O}-\mathrm{CAD}$ and TVD (associations from univariate analyses with $\mathrm{p}<0.1$ ).

The receiver operating characteristics curve (ROC) was used to evaluate the performance of various carotid US parameters and FRS in discriminating $\mathrm{CAD} /$ obstructive CAD. Cut-off values of the carotid US parameters and FRS with best combined sensitivity and specificity were determined according to the Youden index. Net reclassification index (NRI) was used to determine the extend to which employing the new model of carotid US parameters and FRS reclassify high CV risk based on the presence of CAD/O-CAD. A two-tailed probability value of $\mathrm{p}<0.05$ was considered statistically significant.

\section{RESULTS}

\section{Clinical features}

Ninety-one patients (56 (61.5\%) male, age: $50 \pm 11$ years, disease duration: $9.4 \pm 9.2$ years) were recruited. The median $[\mathrm{IQR}]$ interval between CCTA and carotid US assessment was 2 [1-7] months. Majority of patients were having mild to moderate disease activity (DAPSA: 21.3 $\pm 13.3)$. Only $16(18 \%)$ of patients achieved MDA. Most patients $(60 \%)$ were on conventional synthetic diseasemodifying anti-rheumatic drugs (csDMARDs) while only $20 \%$ of patients were on biological DMARDs. Fifty-three (58.2\%), $25(27.5 \%)$ and $13(14.3 \%)$ patients had low, intermediate and high CV risk according to the FRS with a mean FRS of $10.5 \pm 8.9 \%$ (table 1). Other clinical features and traditional CVD risk factors are listed in online supplemental table 1.

\section{Carotid atherosclerosis}

The mean and maximum cIMT were $0.66 \pm 0.11 \mathrm{~mm}$ and $0.81 \pm 0.16 \mathrm{~mm}$, respectively. Carotid plaques were identified in $35(38.5 \%)$ patients [median (IQR) of TPA: $\left.11.89 \mathrm{~mm}^{2}(6.93-17.58)\right]$.

Table 1 Characteristics between patient with and without coronary artery disease and obstructive coronary artery disease

\begin{tabular}{|c|c|c|c|c|c|c|c|c|c|c|}
\hline \multirow{2}{*}{ Demographics } & \multicolumn{2}{|c|}{$\begin{array}{l}\text { No CAD } \\
(n=37)\end{array}$} & \multicolumn{2}{|c|}{ CAD $(n=54)$} & \multirow{2}{*}{$P$ value } & \multicolumn{2}{|c|}{$\begin{array}{l}\text { No obstructive } \\
\text { CAD }(n=82)\end{array}$} & \multicolumn{2}{|c|}{$\begin{array}{l}\text { Obstructive } \\
\text { CAD }(n=9)\end{array}$} & \multirow{3}{*}{$\begin{array}{l}\text { P value } \\
0.028\end{array}$} \\
\hline & & & & & & & & & & \\
\hline Age & 45 & \pm 12 & 53 & \pm 9 & & 50 & \pm 11 & 56 & \pm 7 & \\
\hline Gender, male & 18 & $48.6 \%$ & 38 & $70.4 \%$ & 0.036 & 51 & $62.2 \%$ & 5 & $55.6 \%$ & 0.698 \\
\hline \multicolumn{11}{|l|}{ Disease duration and disease activity } \\
\hline Disease duration (years) & 7.8 & \pm 7.6 & 10.8 & \pm 9.9 & 0.109 & 8.7 & \pm 8.6 & 17.9 & \pm 11.3 & 0.015 \\
\hline DAPSA(0-64) & 20 & $(14,23)$ & 19 & $(10,32)$ & 0.608 & 13 & $(9,21)$ & 6 & $(3,24)$ & 0.972 \\
\hline Achieve MDA & 6 & $16.2 \%$ & 10 & $18.5 \%$ & 0.777 & 13 & $15.9 \%$ & 3 & $33.3 \%$ & 0.191 \\
\hline \multicolumn{11}{|l|}{ Traditional CV risk score } \\
\hline Framingham risk score, \% & 6.3 & \pm 5.6 & 13.3 & \pm 9.7 & $<0.001$ & 9.7 & \pm 8.5 & 17.8 & \pm 9.8 & 0.009 \\
\hline \multicolumn{11}{|l|}{ Framingham 10 year CV risk } \\
\hline Low & 27 & $73.0 \%$ & 26 & $48.1 \%$ & 0.038 & 51 & $62.2 \%$ & 2 & $22.2 \%$ & 0.055 \\
\hline Intermediate & 8 & $21.6 \%$ & 17 & $31.5 \%$ & & 21 & $25.6 \%$ & 4 & $44.4 \%$ & \\
\hline High & 2 & $5.4 \%$ & 11 & $20.4 \%$ & & 10 & $12.2 \%$ & 3 & $33.3 \%$ & \\
\hline Modified Framingham risk score, \% & 9.5 & \pm 8.4 & 20 & \pm 14.5 & $<0.001$ & 14.5 & \pm 12.7 & 26.6 & \pm 14.6 & 0.009 \\
\hline \multicolumn{11}{|l|}{ Modified Framingham 10 year CV risk } \\
\hline Low & 24 & $64.9 \%$ & 15 & $27.8 \%$ & $<0.001$ & 37 & $45.1 \%$ & 2 & $22.2 \%$ & 0.082 \\
\hline Intermediate & 9 & $24.3 \%$ & 16 & $29.6 \%$ & & 23 & $28.0 \%$ & 2 & $22.2 \%$ & \\
\hline High & 4 & $10.8 \%$ & 23 & $42.6 \%$ & & 22 & $26.8 \%$ & 5 & $55.6 \%$ & \\
\hline \multicolumn{11}{|l|}{ Current medication } \\
\hline Anti-hypertensive drug & 6 & $16.2 \%$ & 21 & $38.9 \%$ & 0.021 & 21 & $25.6 \%$ & 6 & $66.7 \%$ & 0.037 \\
\hline Diabetic drug & 2 & $5.4 \%$ & 8 & $14.8 \%$ & 0.188 & 7 & $8.5 \%$ & 3 & $33.3 \%$ & 0.076 \\
\hline NSAIDs & 19 & $51.4 \%$ & 30 & $55.6 \%$ & 0.693 & 44 & $53.7 \%$ & 5 & $55.6 \%$ & 0.303 \\
\hline csDMARDs & 20 & $54.1 \%$ & 34 & $63.0 \%$ & 0.395 & 48 & $58.5 \%$ & 6 & $66.7 \%$ & 0.281 \\
\hline bDMARDs & 5 & $13.5 \%$ & 15 & $27.8 \%$ & 0.017 & 15 & $18.3 \%$ & 5 & $55.6 \%$ & 0.002 \\
\hline
\end{tabular}

Bold values indicate $\mathrm{p}<0.05$

bDMARDs, biologic DMARDs; csDMARDs, conventional synthetic disease-modifying antirheumatic drugs; DAPSA, disease activity in psoriatic arthritis; MDA, minimal disease activity; NSAIDs, non-steroidal anti-inflammatory drugs. 


\section{Coronary artery disease}

Coronary plaques were identified in $54(59.3 \%)$ patients (CAD+ group). Seven (13\%) patients had chest pain. High-risk MP/NCPs were identified in 47 (51.6\%) patients. Twelve $(13.3 \%)$ patients had three-vessel disease and nine $(9.9 \%)$ patients had obstructive CAD. Table 1 summarises the clinical features and traditional CV risk factors of patients with (CAD+ group) and without (CADgroup) coronary plaques.

\section{Identification of CAD by FRS/mFRS}

Twenty per cent and $33 \%$ of patients with CAD and O-CAD were correctly identified as having high CV risk according to FRS (figure 1A,B); the proportion increased to $43 \%$ and $56 \%$, respectively, using the mFRS (figure 1C,D).

\section{Reclassification of CV risk based on the presence of carotid} plaque

Twenty-five out of $78(32 \%)$ patients with low to intermediate CV risk based on the FRS were reclassified as having high CV risk based on the presence of carotid plaque. Sixteen out of these $25(64 \%)$ patients had CAD, and 2/16 (12.5\%) had significant stenosis. Using mFRS, 19 out of $64(30 \%)$ patients with low to intermediate $\mathrm{CV}$ risk based on mFRS were reclassified to high CV risk based on the presence of carotid plaque. Eleven out of $19(58 \%)$ had CAD and 1/19 (11\%) had significant stenosis.
Association of carotid ultrasound parameters in patients with CAD

The mean and maximum (max) cIMT were significantly higher in the CAD+ group compared with the CADgroup (mean cIMT in CAD+ group: $0.69 \pm 0.1 \mathrm{~mm}$ vs CAD - group: $0.63 \pm 0.12 \mathrm{~mm}, \mathrm{p}=0.017$; $\max$ cIMT in CAD + group: $0.84 \pm 0.14 \mathrm{~mm}$ vs CAD- group: $0.77 \pm 0.17 \mathrm{~mm}$, $\mathrm{p}=0.040$ ] (table 2). The prevalence of carotid plaque was similar in both groups. Nonetheless, there was a trend suggesting a larger TPA in the CAD+ group compared with the CAD- group $(\mathrm{p}=0.059)$. Using multivariate logistic regression, increased cIMT was an independent explanatory variable for CAD after adjustment of baseline covariates. The OR for every $0.01 \mathrm{~mm}$ increase in mean cIMT was 1.06 (95\% CI 1.01 to $1.11, \mathrm{p}=0.013$ ) (table 3 ).

Association of carotid ultrasound parameters in patients with 0-CAD

Among the nine patients with lesions rendering over $50 \%$ stenosis of the lumen (O-CAD+ group), only one patient had non-specific chest pain. Four (44\%) patients had all types of plaque, 4 (44\%) patients had NCP only, while 1 (11\%) patient had both CP and MP. Table 1 summarises the clinical features and traditional CV risk factors of the patients with and without O-CAD. The cIMT were significantly higher in the O-CAD+ group when compared with those without significant stenosis (O-CAD- group) [mean cIMT: $0.76 \pm 0.07 \mathrm{~mm}$ vs $0.65 \pm 0.12 \mathrm{~mm}$, respectively,
A.

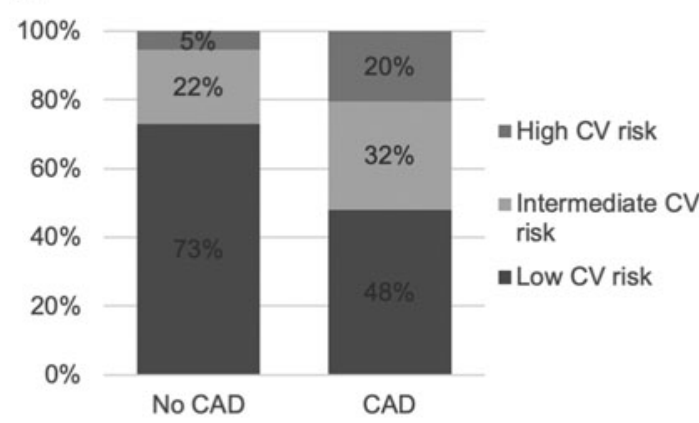

C.

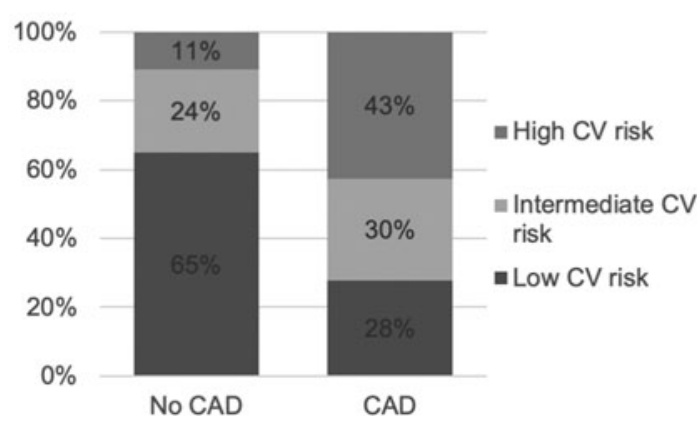

B.

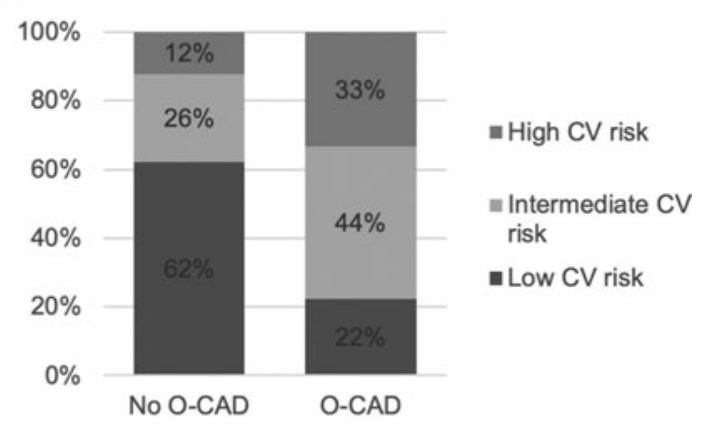

D.

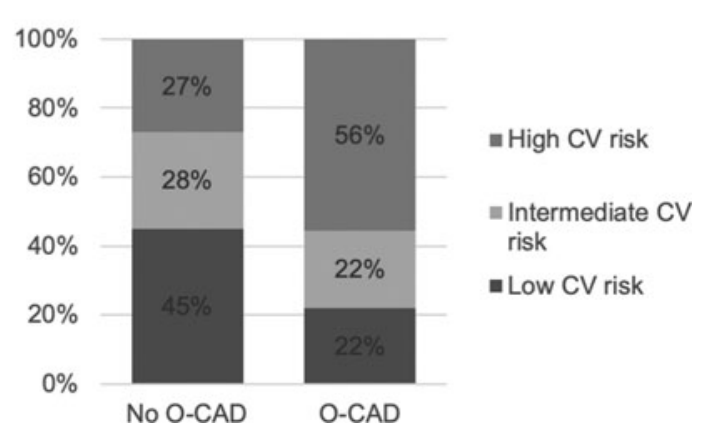

Figure $1 \mathrm{CV}$ risk classification based on Framingham risk score and modified Framingham risk score. CV risk classification based on Framingham risk score (FRS) (A\&B), modified FRS (C\&D) (high CV risk: $\geq 20 \%$; intermediate CV risk: 10-19\%; low CV risk: $<10 \%)$ in patient with or without CAD/O-CAD. 
Table 2 Relationship between carotid ultrasound parameters and the presence and extent of coronary artery disease

\section{Coronary artery disease}

\begin{tabular}{|c|c|c|c|c|c|c|c|}
\hline \multirow{3}{*}{ Mean carotid IMT, mm } & & \multirow{3}{*}{$\begin{array}{l}P \text { value } \\
0.017\end{array}$} \\
\hline & \multicolumn{3}{|c|}{ No $(n=37)$} & \multicolumn{3}{|c|}{ Yes $(n=54)$} & \\
\hline & 0.63 & \pm & 0.12 & 0.69 & \pm & 0.1 & \\
\hline Maximum carotid IMT, mm & 0.77 & \pm & 0.17 & 0.84 & \pm & 0.14 & 0.040 \\
\hline \multicolumn{8}{|l|}{ Carotid plaque, n, \% } \\
\hline Absence & 26 & & $46.4 \%$ & 30 & & $53.6 \%$ & 0.156 \\
\hline Presence & 11 & & $31.4 \%$ & 24 & & $68.6 \%$ & \\
\hline \multirow[t]{3}{*}{ Total plaque area, $\mathrm{mm}^{2}$} & 0.0 & & {$[0,6]$} & 0.0 & & {$[0,10.8]$} & 0.059 \\
\hline & \multicolumn{6}{|c|}{ Obstructive coronary artery disease } & \\
\hline & \multicolumn{3}{|c|}{ No $(n=82)$} & \multicolumn{3}{|c|}{ Yes $(n=9)$} & $P$ value \\
\hline Mean carotid IMT, mm & 0.65 & \pm & 0.12 & 0.76 & \pm & 0.07 & 0.011 \\
\hline Maximum carotid IMT, mm & 0.80 & \pm & 0.16 & 0.93 & \pm & 0.14 & 0.020 \\
\hline \multicolumn{8}{|l|}{ Carotid plaque, n, \% } \\
\hline Absence & 53 & & $93.0 \%$ & 4 & & $7.0 \%$ & 0.235 \\
\hline Presence & 29 & & $85.3 \%$ & 5 & & $14.7 \%$ & \\
\hline \multirow[t]{3}{*}{ Total plaque area, $\mathrm{mm}^{2}$} & 0.0 & & {$[0,7.0]$} & 6.0 & & {$[0,15.3]$} & 0.103 \\
\hline & \multicolumn{6}{|c|}{ Three-vessel disease } & \\
\hline & \multicolumn{3}{|c|}{ No $(n=79)$} & \multicolumn{3}{|c|}{ Yes $(n=12)$} & $P$ value \\
\hline Mean carotid IMT, mm & 0.65 & \pm & 0.12 & 0.72 & \pm & 0.07 & 0.015 \\
\hline Maximum carotid IMT, mm & 0.80 & \pm & 0.16 & 0.87 & \pm & 0.08 & 0.126 \\
\hline \multicolumn{8}{|l|}{ Carotid plaque, n, \% } \\
\hline Absence & 51 & & $91 \%$ & 5 & & $9 \%$ & 0.129 \\
\hline Presence & 28 & & $80 \%$ & 7 & & $20 \%$ & \\
\hline Total plaque area, $\mathrm{mm}^{2}$ & 0.0 & & {$[0,7.0]$} & 6.8 & & {$[0,17.6]$} & 0.050 \\
\hline
\end{tabular}

Bold values indicate $p<0.05$.

O-CAD was defined as $>50 \%$ stenosis of the lumen. Three-vessel disease was defined as presence of coronary plaque in left anterior descendent branch, left circumflex branch and right coronary artery.

IMT, intima mediaintima-media thickness.

Table 3 Multi-variate analysis on association between carotid ultrasound parameters and coronary artery disease and significant stenosis

\begin{tabular}{|c|c|c|c|}
\hline & OR & $95 \% \mathrm{Cl}$ & $P$ value \\
\hline \multicolumn{4}{|c|}{ Presence of coronary artery disease (CAD) ${ }^{\star}$} \\
\hline Mean cIMT (per 0.01 mm) & 1.06 & $1.01-1.11$ & 0.013 \\
\hline \multicolumn{4}{|l|}{ Presence of obstructive CAD } \\
\hline \multicolumn{4}{|l|}{ Model 1-mean IMT } \\
\hline Disease duration (years) & 1.07 & $1.00-1.15$ & 0.070 \\
\hline Use of biologics & 4.30 & $0.96-20.10$ & 0.057 \\
\hline Mean cIMT (per 0.01 mm) & 1.07 & $1.00-1.15$ & 0.042 \\
\hline \multicolumn{4}{|l|}{ Model 2-max IMT } \\
\hline Disease duration (years) & 1.08 & $1.00-1.16$ & 0.047 \\
\hline Use of biologics & 6.03 & $1.20-30.18$ & 0.029 \\
\hline Maximum clMT (per 0.01 mm) & 1.06 & $1.00-1.13$ & 0.043 \\
\hline \multicolumn{4}{|l|}{ Model 3-total plaque area } \\
\hline Disease duration (years) & 1.08 & $1.00-1.17$ & 0.041 \\
\hline Use of biologics & 4.43 & 0.95-20.71 & 0.059 \\
\hline Total plaque area (per $0.1 \mathrm{~mm} \dagger$ ) & 1.55 & $1.01-2.36$ & 0.043 \\
\hline
\end{tabular}

Bold values indicate $p<0.05$

*Adjusted for use of biologics and Framingham risk score. †Adjusted for disease duration, use of biologics and Framingham risk score.

cIMT, carotid intima-media thickness. $\mathrm{p}=0.011 ; \max$ cIMT: $0.93 \pm 0.14 \mathrm{~mm}$ vs $0.80 \pm 0.16 \mathrm{~mm}$, respectively, $\mathrm{p}=0.020$ ] (table 2 ). Using multivariate logistic regression analysis, mean cIMT, max cIMT and TPA were independent explanatory variables associated with O-CAD after adjusting for covariates. The ORs of having O-CAD for every $0.01 \mathrm{~mm}$ increase in mean and max cIMT were 1.07 (95\% CI 1.00 to $1.15, \mathrm{p}=0.042)$ and $1.06(95 \% \mathrm{CI} 1.00$ to $1.11, \mathrm{p}=0.036$ ), respectively, while the $\mathrm{OR}$ for every $0.1 \mathrm{~mm}^{2}$ increase in TPA for significant stenosis was 1.55 (95\% CI 1.013 to $2.359, \mathrm{p}=0.043$ ) (table 3 ).

Association of carotid ultrasound parameters in patients with TVD

Twelve $(13.2 \%)$ patients had TVD. The mean cIMT and TPA were significantly higher for patients with TVD when compared with those without TVD (table 2). No carotid US parameters were identified as independent explanatory variables associated with TVD (results not shown).

Association of carotid ultrasound parameters with presence of calcified plaque, mixed plaque and soft plaque

In general, mean and maximum IMT were significantly higher in patients with calcified plaque, MP and soft plaque, respectively. A trend of a higher TPA was also 
observed in patients with various types of plaque. The association of carotid US parameters in patients with calcified plaque, MP and soft plaque is shown in online supplemental table 2.

The performance of FRS and mFRS at the $20 \%$ cut-off (indicating high $\mathrm{CV}$ risk) in discriminating patients with and without $\mathrm{CAD} / \mathrm{O}-\mathrm{CAD}$ was sub-optimal with low sensitivity (table 4). The optimal cut-offs for FRS in discriminating $\mathrm{CAD}$ and $\mathrm{O}-\mathrm{CAD}$ were $5.2 \%$ and $10.7 \%$, respectively, while the optimal cut-offs for mFRS in discriminating CAD and O-CAD were $7.9 \%$ and $16.1 \%$, respectively.

The performance of mean cIMT was the best among all the carotid US parameters in discriminating patients with and without $\mathrm{CAD}$ ( $\mathrm{AUC}=0.67, \mathrm{p}=0.007$, sensitivity: $76 \%$, specificity: $60 \%$ ). The optimal cut-off for mean cIMT in discriminating CAD was $0.62 \mathrm{~mm}$. Using a combination of mFRS $>8 \%$ and mean cIMT $>0.62 \mathrm{~mm}$, the AUC and specificity for discriminating CAD was increased to $0.74 \%$ and $81 \%$ respectively, although the sensitivity decreased to $67 \%$. Using this combination model of mFRS $>8 \%$ and mean cIMT $>0.62 \mathrm{~mm}, 15$ out of 31
(48\%) patients in mFRS-based low-intermediate CV risk group with $\mathrm{CAD}$ were reclassified to high-risk group with an NRI of $0.33(\mathrm{p}=0.006)$ (table 5).

Discriminatory performance of cIMT for the presence of $\mathrm{O}-\mathrm{CAD}$ was also the best $(\mathrm{AUC}=0.80, \mathrm{p}=0.004$, sensitivity: $78 \%$, specificity: $78 \%$, optimal cut-off: $0.73 \mathrm{~mm}$ ). The combination of mFRS $>16 \%$ and mean cIMT $>0.73 \mathrm{~mm}$ increased the sensitivity to $100 \%$. Nonetheless, the specificity became much lower. The details of other parameters are listed in table 4.

Sub-group analysis in patients without carotid plaque As carotid plaques were only identified in 35 (38.5\%) patients, we performed a sub-group analysis in patients without carotid plaque to address the performance of cIMT in discriminating patients with and without CAD. The mean IMT was higher in patients with CAD $(0.68$ $\pm 0.11 \mathrm{~mm} \mathrm{CAD}+$ group vs $0.62 \pm 0.11 \mathrm{~mm}$ in $\mathrm{CAD}$ - group, $\mathrm{p}=0.035)$. The optimal cut-off of mean IMT for the presence of CAD was $0.65 \mathrm{~mm}$ (AUC: $0.67, \mathrm{p}=0.033$, sensitivity: $70 \%$, specificity: $65 \%)$.

Table 4 Performance of carotid ultrasound parameters and Framingham risk scores in discriminating presence of CAD/ obstructive CAD

\begin{tabular}{|c|c|c|c|c|c|}
\hline & AUC & $P$ value & Cut-off & Sensitivity (\%) & Specificity (\%) \\
\hline \multicolumn{6}{|l|}{ Presence of coronary artery disease (CAD) } \\
\hline \multicolumn{6}{|l|}{ Carotid ultrasound parameters } \\
\hline Mean cIMT & 0.67 & 0.007 & $0.62 \mathrm{~mm}$ & $76 \%$ & $60 \%$ \\
\hline Maximum clMT & 0.65 & 0.017 & $0.77 \mathrm{~mm}$ & $72 \%$ & $57 \%$ \\
\hline Presence of carotid plaque & 0.57 & 0.061 & - & $44 \%$ & $70 \%$ \\
\hline TPA & 0.58 & 0.063 & $11.95 \mathrm{~mm}^{2}$ & $25 \%$ & $94 \%$ \\
\hline \multicolumn{6}{|l|}{ FRS and $m F R S$} \\
\hline FRS & 0.76 & $<0.001$ & $5.2 \%$ & $81 \%$ & $62 \%$ \\
\hline FRS high risk (FRS $\geq 20 \%$ ) & 0.58 & 0.227 & $20 \%$ & $20 \%$ & $95 \%$ \\
\hline mFRS & 0.76 & $<0.001$ & $7.9 \%$ & $81 \%$ & $62 \%$ \\
\hline mFRS high risk (mFRS $\geq 20 \%$ ) & 0.66 & 0.010 & $20 \%$ & $43 \%$ & $89 \%$ \\
\hline \multicolumn{6}{|l|}{ Combination model } \\
\hline FRS $>5 \%$ \& mean clMT $>0.62 \mathrm{~mm}$ & 0.71 & 0.001 & - & $67 \%$ & $76 \%$ \\
\hline $\mathrm{mFRS}>8 \%$ \& mean clMT $>0.62 \mathrm{~mm}$ & 0.74 & $<0.001$ & - & $67 \%$ & $81 \%$ \\
\hline \multicolumn{6}{|l|}{ Presence of obstructive CAD } \\
\hline \multicolumn{6}{|l|}{ Carotid ultrasound parameters } \\
\hline Mean cIMT & 0.80 & 0.004 & $0.73 \mathrm{~mm}$ & $78 \%$ & $78 \%$ \\
\hline Maximum clMT & 0.71 & 0.037 & $0.78 \mathrm{~mm}$ & $100 \%$ & $45 \%$ \\
\hline Presence of carotid plaque & 0.60 & 0.352 & - & $56 \%$ & $65 \%$ \\
\hline TPA & 0.64 & 0.164 & $1.25 \mathrm{~mm}^{2}$ & $44 \%$ & $87 \%$ \\
\hline \multicolumn{6}{|l|}{ FRS and $m F R S$} \\
\hline FRS & 0.76 & 0.012 & $10.7 \%$ & $78 \%$ & $65 \%$ \\
\hline $\mathrm{FRS} \geq 20 \%$ & 0.61 & 0.300 & $20 \%$ & $33 \%$ & $88 \%$ \\
\hline mFRS & 0.76 & 0.012 & $16.1 \%$ & $78 \%$ & $65 \%$ \\
\hline $\mathrm{mFRS} \geq 20 \%$ & 0.64 & 0.159 & $20 \%$ & $56 \%$ & $73 \%$ \\
\hline \multicolumn{6}{|l|}{ Combination model } \\
\hline FRS $>10 \%$ \& mean clMT $>0.73 \mathrm{~mm}$ & 0.71 & 0.045 & - & $56 \%$ & $85 \%$ \\
\hline $\mathrm{mFRS}>16 \%$ and mean cIMT >0.73 mm & 0.71 & 0.045 & - & $100 \%$ & $59 \%$ \\
\hline
\end{tabular}

Bold values indicate $p<0.05$.

cIMT, carotid intima media thickness; FRS, Framingham risk score; mFRS, Modified Framingham risk score; TPA, total plaque area. 
Table 5 Reclassification of combined model when compared with $\mathrm{FRS} \geq 20 \%$ model

\begin{tabular}{ccc}
\hline & NRI & P value \\
\hline Predicting CAD & & \\
FRS $>5 \%$ and mean cIMT $>0.62 \mathrm{~mm}$ & 0.27 & $\mathbf{0 . 0 3 0}$ \\
$\mathrm{mFRS}>8 \%$ and mean cIMT $>0.62 \mathrm{~mm}$ & 0.33 & $\mathbf{0 . 0 0 6}$ \\
Predicting O-CAD & & \\
FRS $>10 \%$ and mean cIMT $>0.73 \mathrm{~mm}$ & 0.20 & 0.224 \\
$\mathrm{mFRS}>16 \%$ and mean cIMT $>0.73 \mathrm{~mm}$ & 0.20 & 0.224 \\
\hline
\end{tabular}

Bold values indicate $\mathrm{p}<0.05$.

CAD, coronary artery disease; cIMT, carotid intima-media thickness; FRS, Framinghamrisk score; mFRS, Modified Framingham risk score; NRI, netreclassification index; O-CAD, obstructive artery disease.

\section{DISCUSSION}

This is the first study to evaluate the association between carotid and CAD focusing on patients with PsA using carotid US and CCTA. We have clearly demonstrated the low sensitivity of using FRS $\geq 20 \%$ as a cut-off in discriminating patients with and without CAD. On the other hand, carotid US parameters including increased cIMT and the extent of carotid plaque (reflected by the TPA) were associated with CAD and significant coronary stenosis. More importantly, mean cIMT has the highest utility in identifying patients in need of further CV risk factor interventions.

We have shown that increased cIMT was an independent explanatory variable associated with CAD in PsA, which concurred with a previous study in patients with inflammatory joint diseases reporting an identical OR of 1.06 for every $0.01 \mathrm{~mm}$ increase in cIMT. ${ }^{21}$ The lack of standardisation of definitions and measurements, together with the high variability and low reproducibility precluded the 2013 American College of Cardiology/ American Heart Association guidelines from recommending cIMT in the assessment of CV risk. ${ }^{6}$ With the advancement of technology, full-length assessment of cIMT in multiple orientations with automated measurement is now possible, which could improve the accuracy and reliability of the assessment. ${ }^{29}$ Indeed, cIMT was able to predict incident $\mathrm{CV}$ event in $\mathrm{PsA}^{17}$ and $\mathrm{RA} .^{30}$

In this study, the presence of carotid plaque alone was unable to discriminate patients with and without CAD or significant stenosis similar to a previous study. ${ }^{21}$ The prevalence of CAD and significant stenosis in patients with carotid plaque were $44 \%$ and $7 \%$, respectively, which was lower than the previous study (the prevalence of CAD and significant stenosis was $65 \%$ and $14 \%$, respectively, for patients harbouring carotid plaque) as we include patients without carotid plaque as well. ${ }^{21}$ These differential findings may be due to the heterogeneous expression of atherosclerosis in carotid and coronary system. ${ }^{31}$ Moreover, carotid plaque might be underestimated by US when compared with carotid CTA. ${ }^{32}$ Whether the presence of carotid plaque may still predict increased risk of developing CV events in PsA patients similar to the general population ${ }^{33}$ and patients with $\mathrm{RA}^{34}$ would need to be confirmed in future studies.

Data from the current study also highlighted an important fact that the absence of carotid plaque does not equal low CV risk, as 30 out of $56(53.6 \%)$ patients in this subgroup had CAD. More importantly, we have demonstrated that mean cIMT could be used to discriminate between patients with or without CAD even in patient without carotid plaque.

As a clinician, we were advised to perform CV risk scores to select high-risk patients for the commencement of statins. Based on the current study, the optimal cut-off for FRS in discriminating CAD was at $5 \%$, similar to $7.3 \%$ in a study with RA patients. ${ }^{35}$ We would definitely under-treat if we choose an FRS cut-off at $20 \%$. Nonetheless, choosing the optimal cut-off at FRS $>5 \%$ most likely will lead to overtreatment. In this scenario, choosing a combination of FRS $>5 \%$ and cIMT $>0.62 \mathrm{~mm}$ could be a reasonable option with a statistically better NRI compared with FRS $\geq 20 \%$. Indeed, a retrospective study has reported that an expanded model of cIMT measurement with FRS, but not the presence of carotid plaque or TPA, provided incremental predictive accuracy for $\mathrm{CV}$ risk reclassification based on $\mathrm{CV}$ events outcome. ${ }^{29}$ Carotid US may not be routinely available in most rheumatologists' practice. Nonetheless, as musculoskeletal US has been widely adopted, this should not be a key limitation with further training by experienced sonographer if further studies have confirmed the clinical utility of this combination model of IMT with FRS in predicting CV events in PsA.

The strength of this study includes the use of CCTA as a surrogate marker of high CV risk, which is closely associated with cardiac events in the general population. ${ }^{11-13}$ Given the high cost and the radiation exposure associated with CGTA, non-invasive carotid US assessment in patients with an FRS $>5 \%$ might be a reasonable tool CV risk stratification for asymptomatic patients. Indeed, carotid US has been recommended as part of the CV risk evaluation in patients with RA. ${ }^{2}$

Our study had some limitations. First, the small number of patients with significant stenosis $(n=9)$, TVD $(n=12)$ and carotid plaque limited the extent of investigation. We did not find that a combination of FRS $>10 \%$ and mean cIMT $>0.73 \mathrm{~mm}$ could enhance reclassification for O-CAD. This finding would need to be confirmed by future study with a larger sample size. Second, high-resolution US may not be very sensitive in detecting carotid plaques, other imaging modalities including carotid CT, MRI or 3D-US might be more useful to assess the association between carotid and coronary atherosclerosis. Third, the current study is investigating the correlation between a combination of FRS and carotid US parameters with the presence of coronary plaque as a surrogate of high CV risk. To date, there are limited data on the association between the presence of coronary plaque and risk of future $\mathrm{CV}$ events in patients of PsA. Future prospective study is warranted to confirm whether these parameters can predict CV events. Fourth, other than CCTA, other potential endpoint using stress test or coronary 
angiogram might also be used in patients with PsA, in whom previous study had shown reasonably association with carotid US parameters. ${ }^{36}$ Last but not least, the subjects in current study had mild to moderate disease activity, whether these findings may be applicable to patients with high disease activity will need to be addressed in the future. In addition, in the era of artificial intelligent (AI) and machined-based learning (ML), new prediction logarithm incorporating both traditional CV risk factors and imaging feature by AI and ML is made possible in general population and patients with RA. Such model might also be extended to patients with PsA and further improve CV risk stratification. $^{37} 38$

\section{CONCLUSION}

While the presence of carotid plaque alone was insufficient to discriminate patients with PsA with or without $\mathrm{CAD}$, a combination of FRS and cIMT may be considered for $\mathrm{CV}$ risk stratification in these patients.

\author{
Author affiliations \\ ${ }^{1}$ Medicine and Therapeutics, The Chinese University of Hong Kong, Hong Kong \\ ${ }^{2}$ Diagnostic and Interventional Radiology, Prince of Wales Hospital, Hong Kong \\ ${ }^{3}$ Medicine and Therapeutics, Prince of Wales Hospital, Hong Kong \\ ${ }^{4}$ Medicine, Tseung Kwan 0 Hospital, Hong Kong \\ ${ }^{5}$ Medicine and Geriatrics, Princess Margaret Hospital, Hong Kong \\ ${ }^{6}$ Medicine, Queen Elizebeth Hospital, Hong Kong \\ ${ }^{7}$ School of Public Health Division of Biostatistics, The Chinese University of \\ Hong Kong Faculty of Medicine, Hong Kong
}

Contributors LST, JJL contributed to study conception and design; ITC, KTW, EKL, PCHW, BTL, ICY, SKY, KYK, ML, TKL, APL, LST contributed to acquisition of data; TIC, KTW, JJL, LST contributed to analysis and interpretation of data. All author contributed to drafting, revising and final approval of article to be published.

Funding This study was supported by the Health and Medical Research Fund (No 01120496).

Competing interests None declared.

Patient consent for publication Not required.

Provenance and peer review Not commissioned; externally peer reviewed.

Data availability statement Data are available upon reasonable request.

Supplemental material This content has been supplied by the author(s). It has not been vetted by BMJ Publishing Group Limited (BMJ) and may not have been peerreviewed. Any opinions or recommendations discussed are solely those of the author(s) and are not endorsed by BMJ. BMJ disclaims all liability and responsibility arising from any reliance placed on the content. Where the content includes any translated material, BMJ does not warrant the accuracy and reliability of the translations (including but not limited to local regulations, clinical guidelines, terminology, drug names and drug dosages), and is not responsible for any error and/or omissions arising from translation and adaptation or otherwise.

Open access This is an open access article distributed in accordance with the Creative Commons Attribution Non Commercial (CC BY-NC 4.0) license, which permits others to distribute, remix, adapt, build upon this work non-commercially, and license their derivative works on different terms, provided the original work is properly cited, appropriate credit is given, any changes made indicated, and the use is non-commercial. See: http://creativecommons.org/licenses/by-nc/4.0/.

\section{ORCID iDs}

Lai-Shan Tam http://orcid.org/0000-0001-6410-8852

\section{REFERENCES}

1 Polachek A, Touma Z, Anderson M, et al. Risk of cardiovascular morbidity in patients with psoriatic arthritis: a meta-analysis of observational studies. Arthritis Care Res (Hoboken) 2017;69:67-74.
2 Agca R, Heslinga SC, Rollefstad S, et al. EULAR recommendations for cardiovascular disease risk management in patients with rheumatoid arthritis and other forms of inflammatory joint disorders: 2015/2016 update. Ann Rheum Dis 2017;76:17-28.

3 D'Agostino RB, Vasan RS, Pencina MJ, et al. General cardiovascular risk profile for use in primary care: the Framingham Heart Study. Circulation 2008;117:743-53.

4 Hippisley-Cox J, Coupland C, Vinogradova Y, et al. Predicting cardiovascular risk in England and Wales: prospective derivation and validation of QRISK2. BMJ (Clinical Research Ed) 2008;336:1475-82.

5 Conroy RM, Pyorala K, Fitzgerald AP, et al. Estimation of ten-year risk of fatal cardiovascular disease in Europe: the SCORE project. Eur Heart J 2003;24:987-1003.

6 Goff DC, Lloyd-Jones DM, Bennett G, et al. 2013 ACC/AHA guideline on the assessment of cardiovascular risk: a report of the American College of Cardiology/American Heart Association Task Force on Practice Guidelines. J Am Coll Cardiol 2014;63:2935-59.

7 Ernste FC, Sanchez-Menendez M, Wilton KM, et al. Cardiovascular risk profile at the onset of psoriatic arthritis: a population-based cohort study. Arthritis Care Res (Hoboken) 2015;67:1015-21.

8 Eder L, Chandran V, Gladman DD. The Framingham risk score underestimates the extent of subclinical atherosclerosis in patients with psoriatic disease. Ann Rheum Dis 2014;73:1990-6.

9 Gulati AM, Semb AG, Rollefstad S, et al. On the HUNT for cardiovascular risk factors and disease in patients with psoriatic arthritis: Population-based data from the Nord-Trondelag health study. Ann Rheum Dis 2016;75:819-24.

10 Shen J, Wong KT, Cheng IT, et al. Increased prevalence of coronary plaque in patients with psoriatic arthritis without prior diagnosis of coronary artery disease. Ann Rheum Dis 2017;76:1237-44.

11 Andreini D, Pontone G, Mushtaq S, et al. A long-term prognostic value of coronary CT angiography in suspected coronary artery disease. JACC Cardiovasc Imaging 2012;5:690-701.

12 Chow BJ, Wells GA, Chen L, et al. Prognostic value of 64-slice cardiac computed tomography severity of coronary artery disease, coronary atherosclerosis, and left ventricular ejection fraction. J Am Coll Cardiol 2010;55:1017-28.

13 Min JK, Dunning A, Lin FY, et al. Age- and sex-related differences in all-cause mortality risk based on coronary computed tomography angiography findings results from the international multicenter CONFIRM (coronary CT angiography evaluation for clinical outcomes: an international multicenter registry) of 23,854 patients without known coronary artery disease. J Am Coll Cardiol 2011;58:849-60.

14 Hou ZH, Lu B, Gao Y, et al. Prognostic value of coronary CT angiography and calcium score for major adverse cardiac events in outpatients. JACC Cardiovasc Imaging 2012;5:990-9.

15 Ahmadi N, Nabavi V, Hajsadeghi F, et al. Mortality incidence of patients with non-obstructive coronary artery disease diagnosed by computed tomography angiography. Am J Cardiol 2011;107:10-16.

16 Szentpetery A, Healy GM, Brady D, et al. Higher coronary plaque burden in psoriatic arthritis is independent of metabolic syndrome and associated with underlying disease severity. Arthritis Rheum 2018;70:396-407.

17 Sobchak C, Akhtari S, Harvey P, et al. Value of carotid ultrasound in cardiovascular risk stratification in patients with psoriatic disease. Arthritis Rheum 2019;71:1651-9.

18 Miller JM, Rochitte CE, Dewey M, et al. Diagnostic performance of coronary angiography by 64-row CT. N Engl J Med 2008;359:2324-36.

19 Lam SH, Shen J, Tam LS, et al. Dr Tam et al. reply. J Rheumatol 2018:45:1330-2.

20 Haroon M, Szentpetery A, Dodd JD, et al. Modifications of cardiovascular risk scores, but not standard risk scores, improve identification of asymptomatic coronary artery disease in psoriatic arthritis. J Rheumatol 2018;45:1329-30.

21 Svanteson M, Rollefstad S, Klow NE, et al. Associations between coronary and carotid artery atherosclerosis in patients with inflammatory joint diseases. RMD Open 2017;3:e000544.

22 Cheng IT, Shang Q, Li EK, et al. Effect of achieving minimal disease activity on the progression of subclinical atherosclerosis and arterial stiffness: a prospective cohort study in psoriatic arthritis. Arthritis Rheum 2019;71:271-80.

23 Coates LC, Fransen J, Helliwell PS. Defining minimal disease activity in psoriatic arthritis: a proposed objective target for treatment. Ann Rheum Dis 2010;69:48-53.

24 Mease PJ. Measures of psoriatic arthritis: tender and swollen joint assessment, Psoriasis Area and Severity Index (PASI), Nail Psoriasis Severity Index (NAPSI), Modified Nail Psoriasis Severity Index (mNAPSI), Mander/Newcastle Enthesitis Index (MEI), Leeds Enthesitis Index (LEI), Spondyloarthritis Research Consortium of Canada (SPARCC), Maastricht Ankylosing Spondylitis Enthesis Score (MASES), Leeds Dactylitis Index (LDI), Patient Global For Psoriatic 
Arthritis, Dermatology Life Quality Index (DLQI), Psoriatic Arthritis Quality of Life (PsAQOL), Functional Assessment of Chronic Illness Therapy-Fatigue (FACIT-F), Psoriatic Arthritis Response Criteria (PsARC), Psoriatic Arthritis Joint Activity Index (PsAJAl), Disease Activity in Psoriatic Arthritis (DAPSA), and Composite Psoriatic Disease Activity Index (CPDAl). Arthritis Care Res (Hoboken) 2011;63:S64-85.

25 Ford ES, Giles WH, Mokdad AH. The distribution of 10-year risk for coronary heart disease among US adults: findings from the national health and nutrition examination survey III. J Am Coll Cardiol 2004;43:1791-6.

26 Budoff MJ, Dowe D, Jollis JG, et al. Diagnostic performance of 64-multidetector row coronary computed tomographic angiography for evaluation of coronary artery stenosis in individuals without known coronary artery disease: Results from the prospective multicenter ACCURACY (assessment by coronary computed tomographic angiography of individuals undergoing invasive coronary angiography) trial. J Am Coll Cardiol 2008;52:1724-32.

27 Austen WG, Edwards JE, Frye RL, et al. A reporting system on patients evaluated for coronary artery disease. Report of the ad hoc committee for grading of coronary artery disease, council on cardiovascular surgery, American heart association. Circulation 1975;51:5-40.

28 Tam LS, Shang Q, Li EK, et al. Subclinical carotid atherosclerosis in patients with psoriatic arthritis. Arthritis Rheum 2008:59:1322-31.

29 Saba L, Jamthikar A, Gupta D, et al. Global perspective on carotid intima-media thickness and plaque: should the current measurement guidelines be revisited? Int Angiol 2019;38:451-65.

30 Gonzalez-Juanatey C, Llorca J, Martin J, et al. Carotid intima-media thickness predicts the development of cardiovascular events in patients with rheumatoid arthritis. Semin Arthritis Rheum 2009;38:366-71.

31 La Grutta L, Marasa M, Toia P, et al. Integrated non-invasive approach to atherosclerosis with cardiac CT and carotid ultrasound in patients with suspected coronary artery disease. Radiol Med 2017;122:16-21.

32 Ramanathan R, Dey D, Norgaard BL, et al. Carotid plaque composition by CT angiography in asymptomatic subjects: a head-to-head comparison to ultrasound. Eur Radiol 2019;29:5920-31.

33 Wyman RA, Mays ME, McBride PE, et al. Ultrasound-detected carotid plaque as a predictor of cardiovascular events. Vasc Med 2006;11:123-30.

34 Evans MR, Escalante A, Battafarano DF, et al. Carotid atherosclerosis predicts incident acute coronary syndromes in rheumatoid arthritis. Arthritis Rheum-us 2011;63:1211-20.

35 Dessein PH, Corrales A, Lopez-Mejias R, et al. The framingham score and the systematic coronary risk evaluation at low cutoff values are useful surrogate markers of high-risk subclinical atherosclerosis in patients with rheumatoid arthritis. J Rheumatol 2016;43:486-94.

36 Hensley B, Huang C, Cruz Martinez CV, et al. Ultrasound measurement of carotid intima-media thickness and plaques in predicting coronary artery disease. Ultrasound Med Biol 2020;46:1608-13.

37 Khanna NN, Jamthikar AD, Gupta D, et al. Rheumatoid arthritis: atherosclerosis imaging and cardiovascular risk assessment using machine and deep learning-based tissue characterization. Curr Atheroscler Rep 2019;21:7.

38 Jamthikar A, Gupta D, Khanna NN, et al. A special report on changing trends in preventive stroke/cardiovascular risk assessment via B-mode ultrasonography. Curr Atheroscler Rep. 2019;21:25. 